DOI: 10.5824/1309-1581.2018.1.007.x

http://www.ajit-e.org/?menu=pages\&p=details_of_article\&id=266

Received : 11.09.2017

Editorial Process Begin: 17.10.2018

Published: 12.02 .2018

\title{
Açık ve Uzaktan Öğrenme Sisteminde Karekod Kullanımı: Açıköğretim Ders Kitapları Örneği
}

\author{
Aras BOZKURT, Anadolu Üniversitesi, Açıköğretim Fakültesi, arasbozkurt@gmail.com , https://orcid.org/0000- \\ $\underline{0002-4520-642 X}$ \\ Abdulkadir KARADENiz, Anadolu Üniversitesi, Açıöğretim Fakültesi, abdulkadir.karadeniz@gmail.com, \\ https://orcid.org/0000-0001-9364-8786 \\ Erdem ERDOĞDU, Anadolu Üniversitesi, Açıöğretim Fakültesi, erdeme@ anadolu.edu.tr, \\ https://orcid.org/0000-0001-5083-7982
}

Öz

Bu çalışmanın temel amacı açık ve uzaktan öğrenme süreçlerinde kullanılan basılı kitaplarda yer alan karekodları incelemektir. Bu amaç doğrultusunda on maddelik bir anket geliştirilmiş ve tarama çalışması yapılmıştır. Araştırma sonuçlarına göre erken benimseyenler olarak tanımlanabilecek bir öğrenci kitlesi karekod teknolojini kullanmaktadır. Araştırma bulgularına göre açık ve uzaktan öğrenme sisteminde yer alan öğrenenlerin karekod teknolojisini öğrenme hedeflerini hızl bir şekilde gerçekleştirmek, etkileşimi artırmak, öğrenme performansın artırmak, öğrenme sürecinde verimliliği artırmak ve öğrenmeyi kolaylaştırmak bağlamında olumlu düşüncelere sahip olduklarl; karekod teknolojini kullanmanın kolay olduğu ve öğrenenlerin bu teknolojiyi başkalarına tavsiye edebilecekleri ortaya çıkmıştır. Çalışmanın devamında karekod teknolojini basılı kitaplarda kullanmanın üstünlükleri ve sınırlıkları açıklanmış ve ileri çalışmalar için önerilerde bulunulmuştur.

Anahtar Kelimeler: Açık ve uzaktan öğrenme, eğitim teknolojileri, karekod, mobil öğrenme, ortam zenginliği kuramı.

\section{The use of the QR Code in Open and Distance Learning: Case of Open Education Faculty Course Books}

\begin{abstract}
The main purpose of this study is to examine the $Q R$ codes in the printed books used in the open and distance learning processes. For this purpose, a ten-item questionnaire was developed, and a survey study was conducted. According to the results of the research, a student population that can be defined as early adopters uses $Q R$ code technology. According to research findings, it is found that learners in open and distance learning system have positive thoughts in order to reach the learning objectives rapidly with $Q R$ code technology, to increase interaction, to improve learning performance, to increase effectiveness in learning process and to facilitate learning. It is also found that $Q R$ code technology is easy to use and learners would recommend this technology to others. In following sections of the study, the strengths and limitations of using QR code technology in printed books was explained and suggestions for future studies were provided.
\end{abstract}

Keywords : Open and distance learning, educational technologies, $Q R$ code, mobile learning, media richness theory. 


\section{Giriş}

Açık ve Uzaktan Öğrenme (AUÖ) sistemi öğrenenlere yaşam boyu eğitim fırsatını sunan bir eğitim modelidir. Bu sistem içerisinde yer alan öğrenenlerin öz-yönelimli ve özdenetimli olmalarından dolayı, AUÖ sisteminde kullanılan eğitim malzemelerinin öğrenenlerin kendi kendine öğrenmeye uygun olarak tasarımlanması, öğrenenlerin daha etkili ve verimli bir öğrenme deneyimi yaşayabilmelerine olanak sağlamaktadır. Bu noktadan hareketle AUÖ sistemi içerisinde yer alan malzemeler öğrenme içeriğini zengin bir biçimde sunmayı amaçlamaktadır. Günümüzde bilgi ve iletişim teknolojileri (BİT) ile ortaya çıkan fırsatlar zengin öğrenme malzeme ve içeriklerinin sunulmasına olanak sağlamaktadır. Her ne kadar öğrenme malzemeleri ve içerikleri BİT’ler ile zenginleştirilse de günümüzde hala en çok tercih edilen öğrenme malzemelerinden birisi de geleneksel basılı kitaplardır. Kitaplar, öğrenme içeriğini etkili ve verimli bir biçimde sunabilmesi için bir öğretim/öğrenme tasarımı çerçevesinde hazırlanmaktadır. Ancak basılı kitaplar kullanılan malzemenin doğası gereği statik bir yapıya sahiptir. Basılı kitapların bu sınırlılı̆̆ını ortadan kaldırabilmek için bir takım tasarım unsurları ve teknolojiler kullanılmaktadır. Bunlardan birisi de mobil teknolojilerin kullanılmasıyla zengin içeriği sağlayabilecek karekod (Quick response code: QR code) teknolojisidir.

\section{Alanyazın Taraması}

Çalışmanın bu kısmında karekod teknolojisi tanıtılmış, eğitimde karekod teknolojisinin kullanımı ve mobil öğrenme konuları açıklanmıştır.

\section{Karekod: İki boyutlu veri şifreleme teknolojisi}

Karekod (QR code), 1994 yılında Japon firması Denso Wave tarafından icat edilmiştir (Kato, Tan ve Chai, 2010). İngilizce kullanımında yer alan QR code ifadesi Türkçe “hızlı yanit kodu" anlamındaki "quick response code" ifadesinin kısaltmasıdır. Karekod bilgiyi iki boyutlu geometrik bir yüzeye şifreleme yöntemidir (Şekil 1). Karekodlar bilgiyi yatay ve dikey doğrultuda şifreleyebilir ve dolayısıyla büyük miktarda veriyi saklama kabiliyetine sahiptir (Kouninef, Merad ve Djelti, 2015; Goyal, Yadav ve Mathuria, 2016; Lee, Lee ve Kwon, 2011; Lezhebokov, Kravchenko ve Bova, 2014; Yfantis, Kalagiakos, Kouloumperi \& Karampelas, 2012; Winter, 2011). Karekodlarda dört çeşit verinin şifrelenip depolanması mümkündür. Bunlar numerik (7089 karakter), alfanumerik (4296 karakter), byte/ikili (2953 karakter) ve Kanji (1817 karakter) verilerdir (Kouninef, Merad ve Djelti, 2015; Lezhebokov, Kravchenko ve Bova, 2014). 


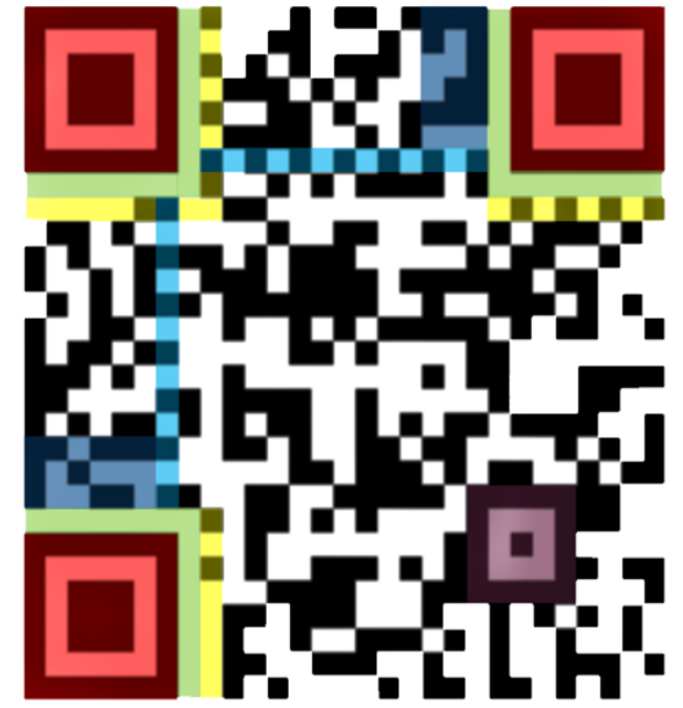

Şekil 1. Karekodun anotomisi

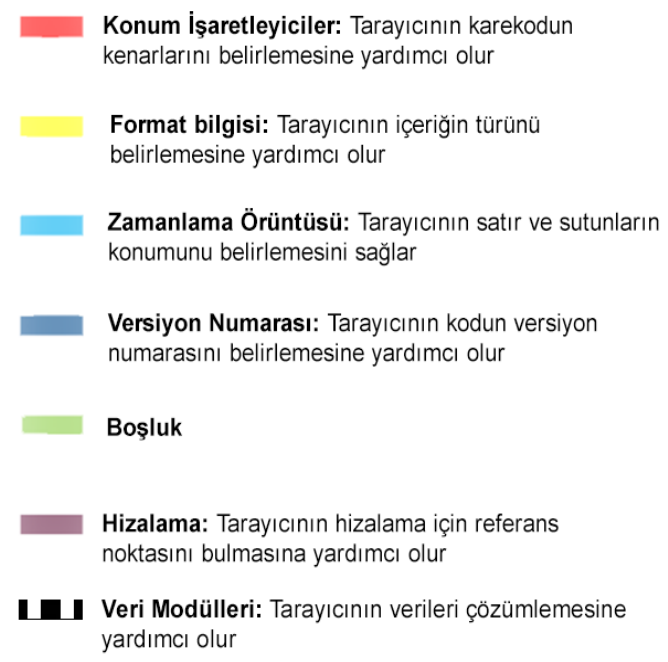

Konum İşaretleyiciler: Tarayıcının karekodun

Format bilgisi: Tarayıcının içeriğin türün belirlemesine yardımcı olur

Zamanlama Örüntüsü: Tarayıcının satır ve sutunların konumunu belirlemesini sağlar

Versiyon Numarası: Tarayıcının kodun versiyon umarasını belirlemesine yardımcı olur yardımcı olur

Karekodlar, geometrik yüzeye sayısal, sözel veya görsel verileri belirli alogoritmalar kullanarak şifreleyebilir ve karekodların okutulup çözümlendiği araçlarda bu veriler gösterilebilir (Youan, Chao ve Chunling, 2011). Karekodun şifrelendiği geometrik görselin \%30'u zarar görse bile çözümleme süreci bu durumdan etkilenmez (Lezhebokov, Kravchenko ve Bova, 2014; Lai, Chang, Wen-Shiane, Fan ve Wu, 2013). İki boyutlu karekod teknolojisinin bir takım avantajları vardır. Bunlar kısaca aşağıdaki gibidir (Liu, Tan ve Chu, 2010; Youan, Chao ve Chunling, 2011):

- Karekodlar yüksek veri depoloma kapasitesine sahiptir.

- Bilgiyi saklamanın kolay ve ekonomik şeklidir.

- Basılı hali çok fazla yer kaplamaz.

- Karekod görseli bozulmaya karşı dayanıklıdır.

- 360 dereceden okunabilir.

\section{Eğitimde karekod kullanımı}

Karekodlar ilk olarak otomotiv sektöründe kullanılmış, sunduğu avantajlı durumlardan dolayı farklı alanlarda da kullanılmaya başlanmıştır (Acartürk, 2012; Liu, Tan ve Chu, 2010). Bu alanlardan birisi de eğitimdir (Winter, 2011). Karekodların eğitim alanında kullanılması ile öğrenenlere bilginin sunumu sadece kitap sayfaları ve sınırlı kalmamakta, zengin içeriğin sunumunu eğitim kurumlarının sınırlarının ötesine taşınabilmesine olanak sağlanabilmektedir (Yfantis, Kalagiakos, Kouloumperi ve Karampelas, 2012). Eğitim süreçlerinde karekodların kullanılmasının temel amacı öğrenen, öğreten veya öğrenme kaynakları arasında iletişime aracılık edecek bir köprü oluşturarak farklı biçimlerde 
çevrimiçi ortamda bulunan bilginin paylaşılmasını sağlamaktır (Şekil 2) (Aktaş ve Çaycı, 2013a). Karekod şifrelenen bilgi ile kullanıcılar arasında bir köprü görevi görmekte, bu şekilde hız olgusunun sürekli arttığı günümüzde istenilen bilgiye ulaşmanın daha çabuk gerçekleşmesine olanak tanımaktadır. Karekodlar sahip olduğu teknik özellikler sayesinde geleneksel eğitim materyallerini melez bir yapıya dönüştürmektedir (Aktaş ve Çaycı, 2013b). Ancak karekodlar var olandan yola çıkarak yeni bir bilginin üretilmesini sağlamamakta, bunun yerine mevcut enformasyonun daha hızlı bir şekilde mobil cihazlar vasıtasıyla aktarılmasını kolaylaştırıp hızlandırmaktadır (Aktaş ve Çaycı, 2013a). Bu düşünceler 1şı̆̆ında karekodlar ile öğrenme sürecinde sağlanan hız ve süreklilik ile kesintisiz öğrenme süreçlerinin öğrenenler tarafından deneyimlenebilmesine olanak sağlandığg söylenebilir.

1984 yılından beri yapılan yenilikçi fikirlerin tanıtıldığı teknoloji ve tasarım alanında yapılan konuşmalarla küresel eğilimlere yön veren TED (Technology, Entertainment and Design) konuşmalarında Matas (2011) "Our Choice" isimli etkileşimli e-kitabı tanıtmıştır. Üst düzey etkileşime sahip ilk örneklerden olan bu dijital kitabın dikkat çeken bazı özellikleri şu şekildedir:

- Etkileşim birden fazla kanal ile gerçekleşir.

- Etkileşim, kullanıcı-dijital kitap ve dijital kitap-çevre arasındadır.

- Etkileşimli e-kitabı oluşturan unsurlar kendi arasında da etkileşim halindedir.

- Etkileşim aynı anda birçok bileşen arasında eşzamanlı olarak gerçekleşir.
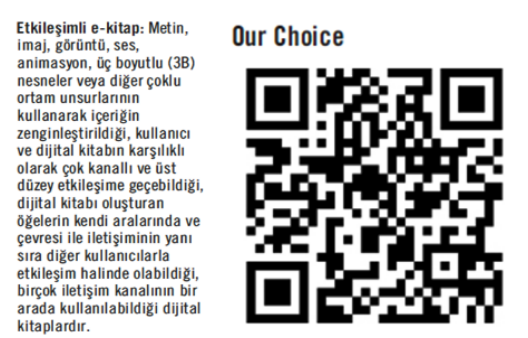

Şekil 2. Basılı kitaplarda örnek karekod kullanımı

İlgili alanyazında yapılan çalışmalar incelendiğinde eğitim süreçlerinde karekod kullanımının etkili olduğu görülmektedir (Lai, Chang, Wen-Shiane, Fan ve Wu, 2013). Yapılan çalışmalar karekodların öğrenme süreçlerinde öğrenenleri motive ettiğini (Lee, Lee ve Kwon, 2011) ve anlamlı öğrenme deneyimleri yaşamalarına olanak sağladığını göstermektedir (Rikala ve Kankaanranta, 2012; Rikala, 2014). Çalışmalar, karekod kullanılan öğrenme süreçlerinde öğrenenlerin daha üretken olduklarını, öğrenenlerin bilgiye çabuk erişebildikleri için daha az stres yaşadıklarını ve ders başarılarının olumlu etkilendiğini ortaya koymaktadır (McCabe ve Tedesco, 2012). Mobil araçların ve karekodların beraber kullanılmalarını inceleyen başka araştırmalar ise bilgiye çabuk erişimin öğrenme sürecine katkı sağladığını (Ozcelik ve Acarturk, 2011) ve öğrenme sürecinin etkililiğini artırdığını göstermektedir (Hwang, Wu, Tseng ve Huang, 2011). İlgili alanyazındaki diğer çalışmalar da ayrıca karekodların kullanımı kolay, etkili ve çekici öğeler olduğunu göstermektedir (Chaisatien ve Akahori, 2007; Durak, Ozkeskin ve Ataizi, 2016; Lai, Chang, Li, Fan ve Wu, 2013; Liu, Tun ve Chu, 200; Law ve So, 2010;PérezSanagustín, Parra, Verdugo, García-Galleguillos ve Nussbaum, 2016 ).

Karekodlar, sağladıkları pratik faydadan dolayı genellikle mobil cihazlar ile kullanılmaktadır. Günümüzde en yaygın mobil araçlardan olan akıllı telefonların çoğunda karekodu okuyup deşifre edebilme yerleşik bir özellik olarak gelmektedir. Basılı yüzey üzerinde belirli algoritmalarla şifrelenen karekod mobil aracın kamerası tarafından 
taranarak okunmakta ve deşifre edilen bilgi çoklu ortam (multimedia) mesajı şeklinde ekrana yansitılabilmekte veya harici kaynaklara yönlendirme yapılabilmesine olanak sağlanabilmektedir (Şekil 3). Mobil araçlarla gelen hareket kabiliyeti, esneklik ve bilgiye anında erişim olanakları öğrenenlerin yüksek derecede etkileşimli içeriğe zaman ve mekân bağlamında sınırlama yaşamadan erişebilmelerine olanak sağlamaktadır.
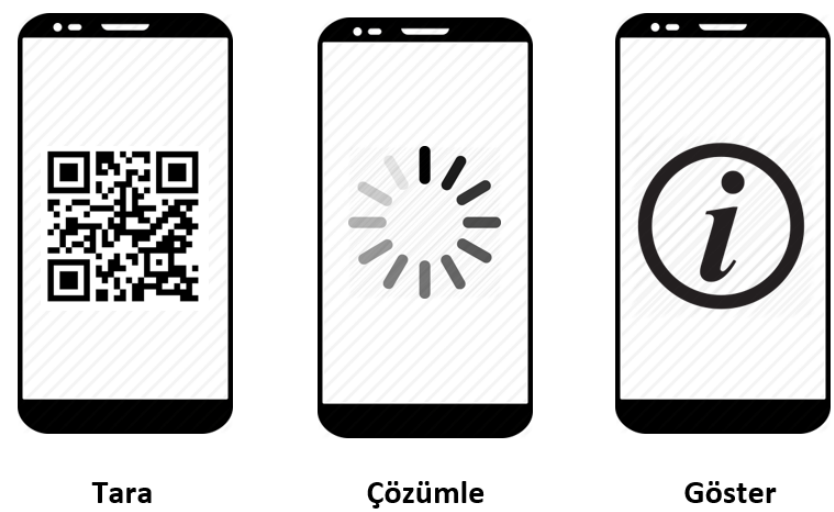

Şekil 3. Karekodun taranıp, çözümlenip, işlenme süreci

\section{Mobil öğrenme ve kesintisiz öğrenme deneyimi}

Mobil öğrenme, mobil araçlar veya mobil ortamlar aracılığıyla gerçekleşen her türlü öğrenme ve öğretme etkinliği şeklinde tanımlanmaktadır (Trifonova, 2003). Yeni milenyumla beraber öğrenenlerin sürekli hareket hâlinde olmaları (göçebe yaşam anlayışı), öğrenme malzemelerine istedikleri zaman istedikleri yerden erişebilmeye ihtiyaç duymaları mobil öğrenmenin yaygınlaşmasına neden olmuştur (Bozkurt, 2015). Mobil öğrenmeyle beraber öğrenme sürecinin farklı bağlamlarda devam etmesi ve süreklilik göstermesi şeklinde tanımlanan kesintisiz öğrenme deneyimi giderek yaygınlaşmaktadır (Looi vd, 2010).

Mobil cihazların kolay taşınabilir olması, esneklik bağlamında sınırlıklara sahip geleneksel öğrenme ortamları ve malzemeleriyle beraber kolayca kullanılabilmesi (Loi vd., 2009), başka bir ifadeyle öğrencilerin basılı materyaller üzerindeki bilgiyi mobil cihazlar ile daha kolay ve daha zengin bir biçimde ulaşabilmesi mobil cihazları iki farklı ortamda (basılı ve dijital) yer alan malzemeler arasında kolay geçiş yapılabilmesine olanak sağlayan teknolojiler olarak öne çıkarmaktadır (Acartürk, 2012).

\section{Kuramsal Çerçeve}

Ortam Zenginliği Kuramı'na göre (Media Richness Theory) ortamın zenginliği; bilginin farklı kanallardan aktarılabilmesi, anlık geri bildirimin sağlanabilmesi ve öğrenenlerin ilgili ortamda var olan unsurlarla yüksek derecede etkileşime geçebilmesi şeklinde açıklanmaktadır (Daft ve Lengel, 1984; Daft ve Lengel, 1986; Daft, Lengel ve Trevino, 1987). İletişimin etkililiği mesaja uygun zenginlikte ortamların kullanılmasıyla ilgilidir (Daft ve Lengel, 1984). Ortam zenginliği Kuramı'na göre anlaşılması zor içeriklerin zengin iletişim 
kanallarıyla beslenmesi mesajın anlaşılmasını daha kolay kılar (Suh, 1999). Dolayısıyla öğrenme süreçlerinde mesajın etkililiği için içerik sunumunun zenginleştirilmesine ihtiyaç vardır (Carlson \& Zmud, 1999). AUÖ sisteminde kullanılan basılı kitaplar doğaları gereği içeriği sadece sözel (basılı metin) ve görsel (haritalar, şekiller, fotoğraflar vs.) kanallar ile sunabilmektedir ve sunulan içerik kitabın fiziksel hacmiyle sınırlıdır. Bu bağlamda karekodların kullanımı ile statik içeriklerin yanı sıra dinamik içeriklerin de basılı kitaplarda sunumu mümkün olmuş, bu çalışmada ise basılı kitaplarda karekod kullanımı ortam zenginliği kuramı bakış açısıyla incelenmiştir.

\section{Amaç}

Yukarıda ifade edilen tartışmalar ışığında bu çalışmanın genel amacı AUÖ sistemlerinde kullanılan kare kod teknolojisini incelemektir. Bu genel amaç doğrultusunda çalışmada aşağıdaki araştırma sorularına yanıt aranmıştır? AUÖ sisteminde kullanılan basılı kitaplarda;

- karekod teknolojisinin kullanım ve kabul düzeyi nedir?

- karekod teknolojisine yönelik öğrenci görüşleri nedir?

- karekod teknolojisinin avantajları ve dezavantajları nelerdir?

\section{Metodoloji}

\section{Araştırma yöntem ve modeli}

Bu çalışmada nicel araştırma yöntemlerinden tarama (survey) çalışması kullanılmış ve araştırma amacı doğrultusunda kesitsel desen (cross-sectional design) benimsenmiştir. Tarama çalışmaları genellikle geniş kitlelerin özelliklerini betimlemeye çalışan çalışmalardır. Bu tür çalışmalarda "ne, nerede, ne zaman, hangi sıklıkla, hangi düzeyde, nasıl" gibi sorulara cevap aranır (Büyüköztürk, Çakmak, Akgün,., Karadeniz, \& Demirel, 2008). Kesitsel tarama çalışmaları hedeflenen örneklemin belirli bir zaman dilimi içerisinde tutumlarını, düşüncelerini, inançlarını ve davranışlarını belirlemek için kullanılır (Creswell, 2004).

\section{Örneklem}

Bu çalışmanın evreni Anadolu Üniversitesi Açıköğretim sisteminde kayıtlı öğrencilerdir. Anadolu Üniversitesi (2017) verilerine göre Türkiye' de Açıöğretim sisteminde 2016-2017 eğitim öğretim yılı itibariyle yaklaşık olarak 1.107.776 aktif Açıöğretim Fakültesi öğrencisi vardır. Çalışmaya 2264 Açıköğretim Fakültesine kayıtlı öğrencisi katılmış, birinci filtre sorusundan sonra 197 öğrenciden veri toplanmıştır. Çalışma \%90 güven aralığında, \%1,73 hata payına sahiptir. Dolayısıyla veri toplanan örneklemin temsil gücünün yüksek olduğu söylenebilir.

\section{Veri toplama aracı ve verilerin analizi}


Bu çalışmada araştırmaçlar tarafından çevrimiçi bir anket geliştirilmiş ve Anadolu Üniversitesi öğrenme yönetimi sisteminde (ÖYS) yayınlanmıştır. Anket toplam 12 maddeden oluşmaktadır. Anketin birinci maddesi öğrenenlerin basılı kitaplarda karekod kullanımını belirlemeye yönelik sorulmuş, ayrıca filtre sorusu olarak kullanılmıştır. Karekod kullanmadıklarını ifade eden öğrenenler için anket sona erdirilmiş, kullandıklarını ifade eden öğrenenlere ise diğer anket maddeleri açılmıştır. Ankette 2. ve 8. maddeler arasında 5'li Likert tipi ölçek kullanılarak öğrenen tutumları belirlenmeye çalışılmıştır. Anketin 9. ve 10. maddeleri yarı yapılandırılmış açık uçlu soru şeklinde eklenmiş, karekodların avantaj ve dezavantajlarına yönelik yanıtlar aranmıştır. Anketin son iki maddesi ise öğrenenlerin demografik bilgilerini öğrenmek için kullanılmıştır. Elde edilen sayısal veriler yüzde, ortalama, frekans ve standart sapma gibi betimsel istatistikler kullanılarak analiz edilmiş, cinsiyet ve yaş bağlamında incelenmiş; tablo ve grafikler ile raporlaştırılmıştır. Sözel veriler ise içerik analizi yoluyla incelenmiş; elde edilen bulgular doğrudan alıntılarla raporlaştırılmıştır.

\section{Bulgular ve Tartışma Demografik bulgular}

Çalışmaya 2264 Açıköğretim öğrencisi katılmış, katılımcıların karekod kullanıp kullanmadıklarını sorgulayan filtre sorusuna 197 katılımcı yanıt vermiştir. Çalışma kapsamında karekod kullandıklarını ifade eden öğrencilerin demografik bilgileri toplanmıştır. Buna göre katılımcıların \%67'si erkek, \%33’ü ise kadındır (Tablo 1).

Tablo 1. Katılımcıların cinsiyetlerine göre demografik dağılımı

\begin{tabular}{lll}
\hline Cinsiyet & Frekans & Yüzde \\
\hline Erkek & 132 & 67 \\
Kadın & 65 & 33 \\
\hline
\end{tabular}

Katılımcıların demografik bilgileri yaşlarına göre incelendiğinde katılımcıların 18-64 yaş aralığında oldukları görülmektedir. Katılımcıların (n=197) genel yaş ortalaması 33,64'tür. Erkek katılımcıların ( $\mathrm{n}=132)$ yaş ortalaması 35,04; kadın katılımcıların yaş ortalaması ise 33,64'tür. Katılımcıların erkek ve kadın olarak sınıflandırılması ile hazırlanan çizgi ve kutu-bıyık grafiğine göre erkek öğrencinin kadın öğrenciye göre daha fazla yaş aralığında karekodları kullandıkları görülmektedir (Şekil 4) (Tablo 2). 

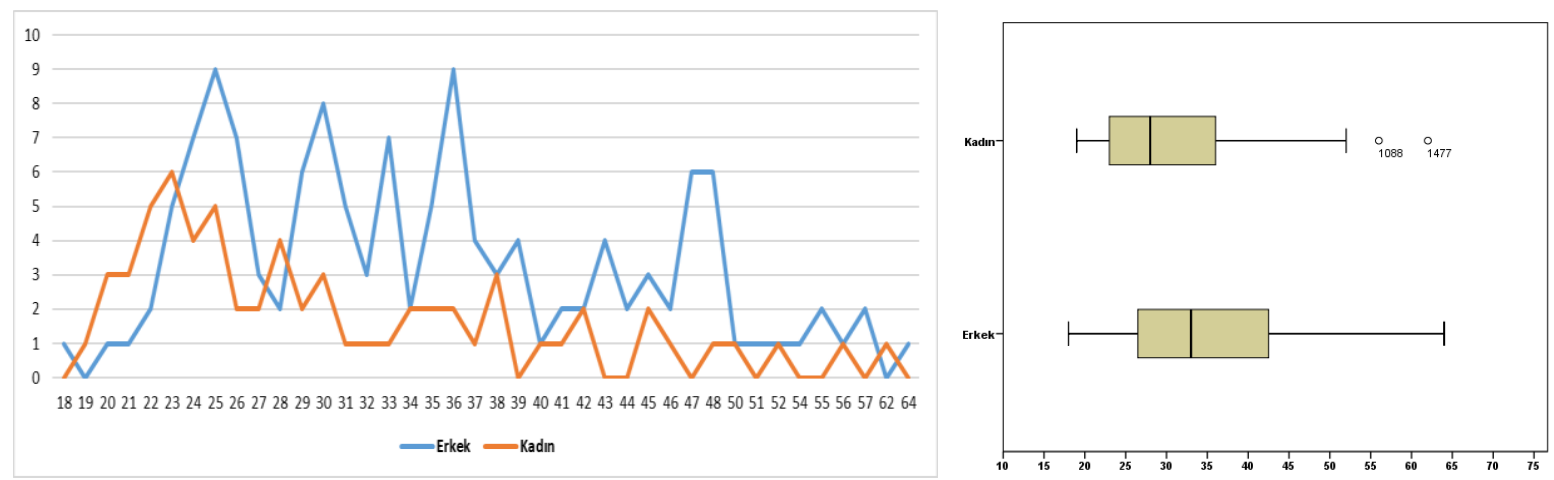

Şekil 4. Katılımcıların yaşlarına göre dağılımı

Tablo 2. Katılımcıların cinsiyetlere göre yaşlarının dağılımı

\begin{tabular}{|c|c|c|c|c|c|c|}
\hline \multirow[t]{2}{*}{ Yaş } & \multicolumn{2}{|c|}{ Erkek } & \multicolumn{2}{|c|}{ Kadın } & \multicolumn{2}{|c|}{ Toplam } \\
\hline & F & $\%$ & F & $\%$ & F & $\%$ \\
\hline $18-22$ & 5 & 2,5 & 12 & 6,1 & 17 & 8,6 \\
\hline $23-26$ & 28 & 14,2 & 17 & 8,6 & 45 & 22,8 \\
\hline $27-30$ & 19 & 9,6 & 11 & 5,6 & 30 & 15,2 \\
\hline $31-34$ & 17 & 8,6 & 5 & 2,5 & 22 & 11,2 \\
\hline $35-38$ & 21 & 10,7 & 8 & 4,1 & 29 & 14,7 \\
\hline $39-42$ & 9 & 4,6 & 4 & 2,0 & 13 & 6,6 \\
\hline $43-46$ & 11 & 5,6 & 3 & 1,5 & 14 & 7,1 \\
\hline $47-50$ & 13 & 6,6 & 2 & 1,0 & 15 & 7,6 \\
\hline $51-54$ & 3 & 1,5 & 1 & 0,5 & 4 & 2,0 \\
\hline $55-58$ & 5 & 2,5 & 1 & 0,5 & 6 & 3 \\
\hline 59-64 & 1 & 0,5 & 1 & 0,5 & 2 & 1 \\
\hline
\end{tabular}

\section{Karekod değerlendirmesi}

Çalışmaya katılan 2264 öğrenciden \%8,7'sı (n=197) Açıköğretim Fakültesi kitaplarında yer alan karekodları kullandıklarını belirtmiş, \%91,3’ü ise (n=2067) Açıköğretim Fakültesi Kitaplarında yer alan karekodları kullanmadıklarını ifade etmişlerdir (Şekil 5). 


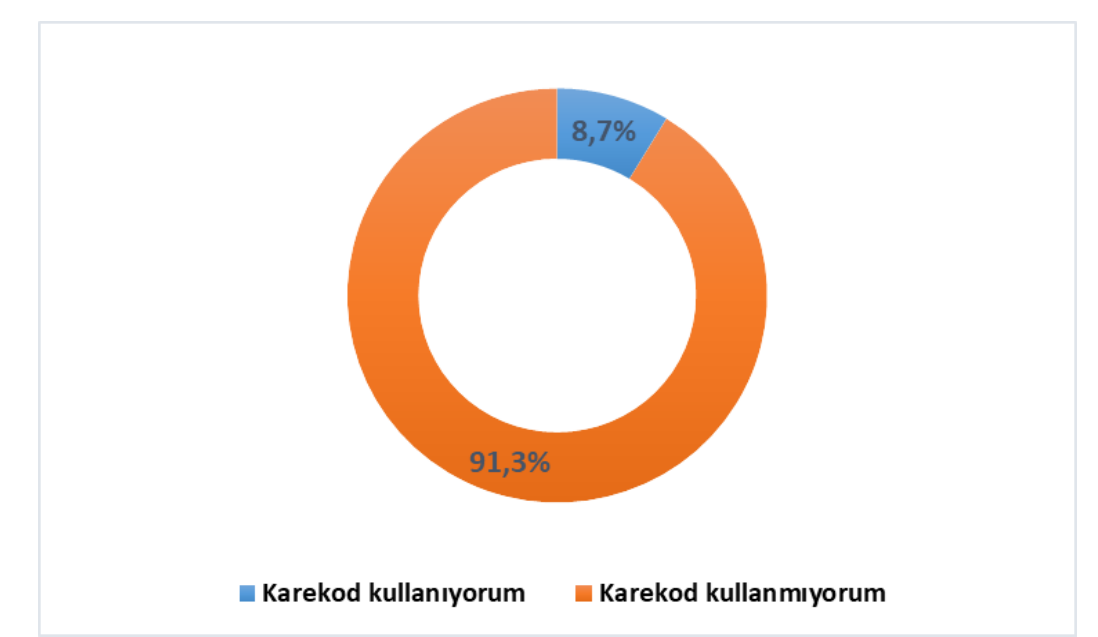

Şekil 5. Açıköğretim Fakültesi öğrencilerinin karekod kullanım oranları

Görüldüğü üzere basılı kitaplarda kullanılan karekod teknolojisinin kullanımı \%8,7'lik bir kullanıcı tarafından tercih edilmektedir. Bu durum Yeniliklerin Yayılımı Kuramında (Diffusion of Innovations) (Rogers, 2010) yer alan açıklamalarla örtüşmektedir. Rogers yeniliği bir ihtiyacı karşılamaya yönelik alternatif çözüm veya yol olarak tanımlanmaktadır. Yenilik bir fikir, ürün veya uygulama olabilir. Yayılma ise yeniliğin bir iletişim sürecinde iletilmesi sürecidir. Yeniliğin yayılması sürecinde toplam beş gruptan bahsedilebilir. Bunlar; yenilikçiler (innovators), erken benimseyenler (early adopters), erken çoğunluk (early majority), geç çoğunluk (late majority) ve tutucular (laggards) şeklindedir (Rogers, 2010). Bu aşamada bu çalışmada yer alan katılımcıların erken benimseyenler olduğu düşünülmektedir. Dolayısıyla karekod teknolojisinin Açıöğretim Fakültesi öğrencileri tarafından bir yenilik olarak kabul görüp yayılabilmesi için, karar verme sürecinde etkili olabilecek ve yeni bir teknoloji olarak kabul görmesini sağlayacak çalışmalara ihtiyaç olduğu düşünülmektedir. Bu bağlamda karar verme aşmasında etkili olabilecek beş unsur üzerinde geliştirmeler yapılmasının etkili olabileceği söylenebilir. Bunlar; göreceli fayda (relative advantage), uygunluk (compatibility), karmaşıklık ya da basitlik (complexity or simplicity), denenebilirlik (trialabilty) ve gözlenebilirlik (observability) şeklindedir.

Çalışmaya katılan ve karekod kullandıklarını ifade eden Açıköğretim Fakültesi öğrencilerinin yanıtları Tablo 3'de verilmiştir. Her bir madde karekod kullanımına yönelik farklı bir özelliği ölçmek için hazırlanmıştır. 1. madde öğrenme hedeflerini gerçekleştirmeye yönelik hız, 2. madde etkileşim, 3. madde öğrenme performansı, 4. madde öğrenme sürecinde verimlilik, 5. madde öğrenme sürecinde sağladığı kolaylık, 6 . madde kullanım kolaylığı ve son olarak 7. madde ise kullanımdan duyulan doyumu ölçmeyi amaçlamıştır. Yanıt ortalamalarının 3,60 ile 3,76 arasında değişmesi, yanıtların olumlu yönde olduğunu göstermektedir. Aralığı 1 olan 5'li likert için standart sapmaların 1,32 ile 1,38 arasında değişmesi ise yanttların ortalamadan ciddi sapmalara uğramadığ 1 ve risk barındırmadığının kanıtıdır. Katılımcıların "katılıyorum (4)" ve "kesinlikle katılıyorum (5)" seçeneklerine verdikleri yantlar incelendiğinde 1. maddeye (hız) \%69; 2 
maddeye (etkileşim) \%71,5; 3. maddeye (performans) \%68; 4. maddeye (verimlilik) \%69; 5 . maddeye (kolaylık) \%65,5; 6. maddeye \%69,5; ve 7. maddeye ise (doyum) \%66 oranında olumlu yanıt verilmiştir. Tablo 3'te verilen betimsel istatistiklere göre Açıöğretim Fakültesi öğrencilerinin kitaplarda karekod kullanımını genel anlamda olumlu buldukları söylenebilir.

Tablo 3. Açıköğretim Fakültesi öğrencilerinin AUÖ sisteminde kullanılan karekod teknolojisine yönelik görüşleri

\begin{tabular}{|c|c|c|c|c|c|c|c|}
\hline Madde & $\begin{array}{l}\text { Madde } \\
\text { Değeri* }\end{array}$ & $\mathbf{F}$ & $\begin{array}{c}\text { Kum } \\
\text { F }\end{array}$ & $\%$ & $\begin{array}{c}\text { Kum } \\
\%\end{array}$ & Ort. & $\begin{array}{c}\text { Standart } \\
\text { Sapma }\end{array}$ \\
\hline \multirow{5}{*}{$\begin{array}{l}\text { 1. Basılı kitaplarda karekod kullanmak } \\
\text { öğrenme hedeflerimi hızlı bir şekilde } \\
\text { gerçekleştirmemi sağlar }(\mathrm{H} 1 \mathrm{z})\end{array}$} & 5 & 67 & 67 & 34,01 & 34,01 & \multirow[t]{5}{*}{3,66} & \multirow[t]{5}{*}{1,389} \\
\hline & 4 & 69 & 136 & 35,03 & 69,04 & & \\
\hline & 3 & 17 & 153 & 8,63 & 77,66 & & \\
\hline & 2 & 16 & 169 & 8,12 & 85,79 & & \\
\hline & 1 & 28 & 197 & 14,21 & 100,00 & & \\
\hline \multirow{5}{*}{$\begin{array}{l}\text { 2. Basılı kitaplarda karekod kullanmak } \\
\text { etkileşimi arttırır (Etkileşim) }\end{array}$} & 5 & 70 & 70 & 35,53 & 35,53 & \multirow[t]{5}{*}{3,76} & \multirow[t]{5}{*}{1,337} \\
\hline & 4 & 72 & 142 & 36,55 & 72,08 & & \\
\hline & 3 & 16 & 158 & 8,12 & 80,20 & & \\
\hline & 2 & 15 & 173 & 7,61 & 87,82 & & \\
\hline & 1 & 24 & 197 & 12,18 & 100,00 & & \\
\hline \multirow{5}{*}{$\begin{array}{l}\text { 3. Basılı kitaplarda karekod kullanmak } \\
\text { öğrenme performansımı arttırır } \\
\text { (Performans) }\end{array}$} & 5 & 63 & 63 & 31,98 & 31,98 & \multirow[t]{5}{*}{3,67} & \multirow[t]{5}{*}{1,328} \\
\hline & 4 & 71 & 134 & 36,04 & 68,02 & & \\
\hline & 3 & 21 & 155 & 10,66 & 78,68 & & \\
\hline & 2 & 19 & 174 & 9,64 & 88,32 & & \\
\hline & 1 & 23 & 197 & 11,68 & 100,00 & & \\
\hline \multirow{5}{*}{$\begin{array}{l}\text { 4. Basılı kitaplarda karekod kullanmak } \\
\text { öğrenme sürecinde verimliliğimi } \\
\text { arttırır (Verimlilik) }\end{array}$} & 5 & 65 & 65 & 32,99 & 32,99 & \multirow[t]{5}{*}{3,69} & \multirow[t]{5}{*}{1,34} \\
\hline & 4 & 71 & 136 & 36,04 & 69,04 & & \\
\hline & 3 & 21 & 157 & 10,66 & 79,70 & & \\
\hline & 2 & 15 & 172 & 7,61 & 87,31 & & \\
\hline & 1 & 25 & 197 & 12,69 & 100,00 & & \\
\hline \multirow{5}{*}{$\begin{array}{l}\text { 5. Basılı kitaplarda karekod kullanmak } \\
\text { öğrenmemi kolaylaştırır (Kolaylık) }\end{array}$} & 5 & 61 & 61 & 30,96 & 30,96 & \multirow[t]{5}{*}{3,6} & \multirow[t]{5}{*}{1,361} \\
\hline & 4 & 68 & 129 & 34,52 & 65,48 & & \\
\hline & 3 & 23 & 152 & 11,68 & 77,16 & & \\
\hline & 2 & 19 & 171 & 9,64 & 86,80 & & \\
\hline & 1 & 26 & 197 & 13,20 & 100,00 & & \\
\hline \multirow{5}{*}{$\begin{array}{l}\text { 6. Basılı kitaplarda karekod } \\
\text { kullanmayı kolay buluyorum } \\
\text { (Kullanım kolaylığı) }\end{array}$} & 5 & 65 & 65 & 32,99 & 32,99 & \multirow[t]{5}{*}{3,69} & \multirow[t]{5}{*}{1,349} \\
\hline & 4 & 72 & 137 & 36,55 & 69,54 & & \\
\hline & 3 & 18 & 155 & 9,14 & 78,68 & & \\
\hline & 2 & 17 & 172 & 8,63 & 87,31 & & \\
\hline & 1 & 25 & 197 & 12,69 & 100,00 & & \\
\hline \multirow{5}{*}{$\begin{array}{l}\text { 7. Basılı kitaplarda karekod } \\
\text { kullanmayı bir arkadaşıma tavsiye } \\
\text { edebilirim (Doyum) }\end{array}$} & 5 & 73 & 73 & 37,06 & 37,06 & \multirow[t]{5}{*}{3,7} & \multirow[t]{5}{*}{1,365} \\
\hline & 4 & 57 & 130 & 28,93 & 65,99 & & \\
\hline & 3 & 26 & 156 & 13,20 & 79,19 & & \\
\hline & 2 & 17 & 173 & 8,63 & 87,82 & & \\
\hline & 1 & 24 & 197 & 12,18 & 100,00 & & \\
\hline
\end{tabular}


${ }^{*} 1=$ Kesinlikle katılımıyorum, 2=Katılmıyorum, 3=Kararsızım, 4=Katılıyorum, 5=Kesinlikle katılıyorum

\section{Karekodların üstünlükleri ve sınırlılıkları}

Açıköğretim Fakültesi öğrencilerine açık uçlu sorularla karekodların üstünlükleri ve sınırlılıkları sorulmuş ve bu şekilde karekod teknolojisinin güçlü ve zayıf yönleri belirlenmeye çalışılmıştır. Katılımcı cevaplarında dikkat çeken ilk nokta basılı teknolojiyle üretilen ve statik bir yapıya sahip olan içeriklerin daha aktif ve etkileşimli bir hale gelmesine yöneliktir. Bu duruma yönelik katılımcı ifadeleri aşağıdaki gibidir:

- Pasif içerik içerisinde aktif içeriği kullanabilmeyi mümkün kılıyor.

- Etkileşim içinde olunuyor.

Buna göre karekodlarla çoklu ortam içeriklerini sunarak etkileşim sağlamak (Clark, ve Mayer, 2016) ve dijital kitaplara benzer bir şekilde kısmen e-okuma deneyimi (Bozkurt ve Bozkaya, 2015) ve AUÖ sistemi içeriklerinde önemli olan öğrenen-içerik etkileşimini (Erdoğdu, 2016) sağlamanın mümkün olduğu söylenebilir.

Bir diğer avantajlı durum ise karekodların öğrenme süreçlerini desteklemesi bağlamında olduğu görülmektedir. Buna göre karekod teknolojileriyle sunulan içerikler öğrenme sürecini daha etkili bir hale getirebilmektedir. Bu düşünceye yönelik katılımcı görüşleri aşağıdaki gibidir:

- Beynimde ders içeriğini sadeleştirerek, belirsizliği azaltıyor. Böylelikle hedefi daha net ve istikrarla hatırlamama katkı sağlıyor.

- Bilgiyi pekiştirmeyi ve o an okuduğun bilgiyi deneyimleyebilmeyi sağlıyor. Görsel olarak bir bilgiye ulaşmak okunan metnin etkisini arttırıyor.

- Çözüme daha kısa sürede ulaşarak anlaşılmayan konunun daha iyi ve çabuk olarak anlaşılmasını sağlayarak pekiştirilmesine yardımcı olması.

Karekod teknolojisinin bir diğer avantajı ise sadece dijital ortamlarda sunulabilen çoklu ortam (multimedia) unsurlarının basılı kitaplar gibi geleneksel ortamlarda da sunulabilmesidir. Başka bir ifadeyle basılı kitaplar ile sadece yazı ve görseller değil; ses, video, animasyon gibi içeriklerinde sunumu olanaklı hale gelmiş, bu durum ise öğrenme süreçlerini desteklemiştir. Bu görüşe yönelik katılımcı yanıtlarından alıntılar aşağıda sunulmuştur:

- Görsel destekleme, pekiştirme, öğrenmeyi eğlenceli hale getirme, farklı bakış açılarını gösterebilme, farklı kaynak gösterimi. 
- Multimedya özelliği nedeniyle duy gör algıla ve yorumla mantığını barındırması.

Bu açıdan ele alındığında dijital öğrenme ortamları için geliştirilen çoklu ortamlardan öğrenme kuramının (Multimedia Learning Theory) bu şekilde geleksel ortamlarda da kullanılabilmesinin mümkün olduğu görülmektedir (Mayer ve Moreno, 2003). Çoklu ortamlardan öğrenme, öğrenmenin kalıcılığını da etkileyen bir unsurdur (Karadeniz, 2011). Bu noktada Clark, ve Mayer (2016) tarafından açıklanan çoklu ortam tasarım ilkelerinin karekodlar aracılığılyla sunulan içeriklere yansıtılması daha etkili ve verimli öğrenme deneyimlerinin elde edilebilmesine olanak sağlayabilir. Bu noktada basılı kitaplarda karekod kullanımında sadece içeriğin sunumuna değil, sunulan içeriğin tasarımına da dikkat edilmesi gereken önemli bir nokta olarak değerlendirilmektedir.

Araştırma katılımcıları tarafından ifade edilen başka bir avantaj ise teknoloji entegrasyonu ile daha hızlı ve kolay bir biçimde içeriğe ulaşılabilmesi şeklindedir. Bu duruma yönelik katılımcı ifadeleri aşağıdaki gibidir:

- Hizlı aktif öğrenme.

- Kolaylık ve pratiklik sağlaması.

- Ulaşmak istediğimiz içeriğe kısa sürede ve kolayca ulaşmamızı sağlıyor.

- Daha fazla teknoloji kullanımı, her yerden ve her zaman ulaşım imkânı.

Teknoloji Kabul Kuramına göre (Davis, 1985) algılanan kolaylık ve algılanan kullanışlılık kullanıma ilişkin tutum ve davranışları belirleyen faktörlerdir. Bununla beraber karekod kullanımının yaygınlaştırılması için fayda ve kolaylık kavramları çerçevesinde mevcut karekod uygulamalarının geliştirilmesi gerektiği söylenebilir.

Karekodların soyut ve anlaşılması zor öğrenme süreçlerini somutlaştırmak ve öğrenme sürecini kolaylaştırmak için kullanılabilmesi ise sahip olduğu bir diğer üstünlük olarak değerlendirilmiştir. Bu düşünceye yönelik katılımcı görüşü aşağıdaki gibidir:

- Anlaşılmayan soruların yanına karekod açılabilir. Mesela matematiksel ya da formüle dayalı konularda çok faydalı olur.

Karekodların sahip oldukları üstünlüklerin yanı sıra bir takım sınırlılıklar da araştırma katılımcıları tarafından ifade edilmiştir. Bunlardan birincisi geleneksel kitap okuma alışkanlığını benimseyen ve seven öğrenenlerin basılı kitap ile öğrenme süreçlerinde teknolojiyi işe koşmak istememeleridir. Bu görüşe yönelik katılımcı yanıtlarından alıntılar aşağıda sunulmuştur:

- Deneme amaçlı birkaç kez okuttum fakat çalışamadım kitap kokusu en iyisi. 
- Kitap sayfalarını elle tutup elle ile çalışmak bir başkadır.

- Geleneksel kitap okuma deneyiminden teknolojiyle zenginleştirilmiş kitap okuma deneyimine geçiş zor olabiliyor...

Bu durum aslında dijital kitaplarla sağlanan e-okuma deneyiminde sıklıkla gözlenebilen bir sınırlılıktır. Buna göre okuyucular çoğu zaman basılı kitapların ağırlığını hissetmek, kokusunu almak ve hatta sayfayı çevirdiklerinde kâğıt sesini duymak istemektedirler (Bozkurt ve Bozkaya, 2015). Bu tür kullanıcılar Yeniliklerin Yayılımı Kuramında (Rogers, 2010) tanimlanan tututcular olarak ta nitelendirilebilir.

Katılımcı yanıtlarının incelenmesi ile ortaya çıkan bir diğer sınırlılık ise karekodların kullanılabilmesi için mobil cihazlar, internet bağlantısı ve temel düzeyde teknoloji okuryazarlığı bilgisine sahip olunması gerektiğidir. Bu duruma yönelik katılımcı ifadeleri aşağıdaki gibidir:

- Cep telefonu modeli. İnternet gereksinimi. Küçük ekran.

- Akıllı telefon haricinde ulaşımı zor.

- Her ne kadar teknolojik bir çağda yaşasak bile her öğrencinin akıllı telefonu olmaya bilir. Bu yönden dezavantajı olabileceğini düşünüyorum.

- Teknolojinin bilinen ve bilinmeyen bazı olumsuz etkileri ile karşı karşıya kalma.

Yine karekodlar ile sunulan içeriklerin kalitesinin düşük olabilmesi çoğu durumda öğrenme sürecini desteklemekten daha çok engelleyen bir durum olarak ortaya çıkabilmektedir. Bu düşünceye yönelik katılımcı görüşleri aşağıdaki gibidir:

- Beklenilen öğrenme bağlantısı verimsizse karekodlar kullanılmayabilir.

- İçerik seçimi ve kavramsallaştırmada yetersizlik.

- Ders çalışma konsantrasyonu dağıtabilmekte ve zaman kaybı yaşanabilmektedir.

\section{Sonuç ve Öneriler}

Bu çalışma bağlamında AUÖ sisteminde kullanılan basılı kitaplarda kullanılan karekod teknolojisi incelenmiş ve Anadolu Üniversitesi, Açıköğretim Fakültesi öğrencilerinin görüşleri belirlenmeye çalışılmıştır. Çalışma bulgularına göre karekod; öğrenme sürecini destekleyen, öğrenme sürecinde hızlı veri alış verişine olanak sağlayan bir köprü teknolojidir. Bu durum Ortam Zenginliği Kuramında bahsedilen varsayımları da doğrulamaktadır. Bununla beraber karekod teknolojisinin Yeniliklerin yayılım Kuramında da açıklandığı gibi "erken benimseyenler" olarak tanımlanabilecek kitle tarafından kullanılan bir teknoloji olduğu, bu teknolojinin yaygınlaştırılması için ise Teknoloji Kabul Kuramında bahsedilen faktörlere yönelik çalışmalar yapılması gerektiği düşünülmektedir. 
Karekod teknolojileriyle sunulan içerikleri ise Çoklu Ortamlardan Öğrenme Kuramında açıklanan prensiplere göre tasarımlanmasının daha etkili olabileceği söylenebilir.

Açıköğretim fakültesi öğrencilerinin karekod kullanımına yönelik tutumları hazırlanan anket maddeleri ile farklı bağlamlarda incelenmiş (hız, etkileşim, performans, verimlilik, kolaylık, kullanım kolaylığı ve doyumu) genel olarak katılımcıların olumlu düşünceleri olduğu belirlenmiştir.

Elde edilen nitel verilerin analizi ile Karekodların pasif/durağan yapıdaki basılı kitap içeriklerinin daha etkileşimli hale getirdiği, öğrenme sürecini ve öğrenilen bilgiyi pekiştirmeyi kolaylaştırdığı, karekod teknolojisiyle sunulan çoklu ortam içeriklerinin öğrenme sürecini olumlu etkilediği sonucuna varılmıştır. Bununla beraber karekod teknolojini kullanabilmek için başka teknolojilere ihtiyaç olması, bazı öğrencilerin geleneksel sistemleri tercih etmesi, karekod ile sunulan içeriklerin öğretim tasarımı yapılmadan sunulması gibi durumlar ise mevcut sınırlılıklar olarak değerlendirilmiştir.

İlgili alanyazında yer alan tartışmalar ve bu çalışma bulguları ışığında aşağıda açıklanan yönelimler ileri çalışmalar için önerilmektedir.

- Karekod teknolojisi ile farklı multimedya içeriklerin sunumu mümkündür. Bununla beraber basılı materyallerde yer alan içerik türüyle karekodlar aracilığıyla sağlanan içerikler arasında bir uyum olması gerektiği, yanlış tasarımların öğrenende bilişsel yük oluşturulabileceği unutulmamalıdır. Dolayısıyla karekodların kullanımına yönelik bilişsel yük ve ikili kodlama kurmaları çerçevesinde yapılacak çalışmaların ilgili alanyazına katkı sağlayacağı düşünülmektedir

- Karekodlar aracılığıyla öğrenenlere basılı içeriğe ek olarak zengin içerik sunulması amaçlanmaktadır. Bununla beraber sunulan içeriklerin yoğunluğu ve uzunluğu basılı kitap aracılığıyla sağlanması planlanan öğrenme deneyimi sürecini sekteye uğratmayacak şekilde tasarımlanmalı, öğrenenlerin odaklanma süreleri gibi değişkenler ile ileri çalışmalar yapılması önerilmektedir.

- Karekodların açık ve uzaktan öğrenme süreçlerinde kullanılmasına yönelik çalışmaların Yeniliklerin Yayılımı, Teknoloji Kabul kuramı, Ortam Zenginliği ve Çoklu Ortamlardan Öğrenme Kuramları çerçevesinde incelenmesinin daha etkili, verimli ve çekici karekod uygulamalarını tasarımlanıp uygulanmasına katkı sağlayacağ1 düşünülmektedir. Dolayısıyla ileri çalışmaların bu kuramsal yaklaşımlar üzerine yapılandırılmasının faydalı olacağı düşünülmektedir.

- Karekodların doğrudan öğrenmeyi değil, öğrenme süreçlerinde kullanılan süreçleri hızlandırmaya, desteklemeye ve zenginleştirmeye yönelik bir teknoloji olduğu ve 
ileri araştırmaların bu yönde ilerlemesi gerektiği düşünülmektedir. Her ne kadar karekod teknolojisi birçok alanda sıklıkla kullanıyor olsa da karekodların nasıl daha etkili kullanılabileceğine yönelik kriterlerin geliştirilmesine ihtiyaç vardır

\section{Kaynakça}

Acartürk, C. (2012). Barkod teknolojilerinin eğitimde kullanımı: Bilişsel bilimler çerçevesinde bir değerlendirme. Akademik Biliş̧im'12 - XIV. Akademik Bilişim Konferansı Bildirileri (s. 117-122). 1-3 Şubat 2012, Uşak Üniversitesi.

Aktaş, C. ve Çaycı, B. (2013a). QR kodların eğitim teknolojilerinde kullanımı. International Conference on Communication, Media, Technology and Design, 375-379.

Aktaş, C., \& Çaycı, B., (2013b). QR kodun mobil eğitimde yeni eğitim yöntemlerinin geliştirilmesine katkısı. Global Media Journal, 4(7), 1-19.

Bozkurt, A. \& Bozkaya, M. (2015). Evaluation criteria for interactive e-books for open and distance learning. International Review of Research in Open and Distributed Learning, 16(4), 58-82

Bozkurt, A. (2015). Mobil öğrenme: her zaman, her yerde kesintisiz öğrenme deneyimi. Açı Öğretim Uygulamaları ve Araştırmaları Dergisi (AUAd), 1(2), 65-81.

Büyüköztürk, Ş., Çakmak, E. K., Akgün, Ö. E., Karadeniz, Ş., \& Demirel, F. (2008). Bilimsel Araştırma Yöntemleri. Ankara: Pegem Akademi.

Carlson, J. R. \& Zmud, R. W. (1999). Channel expansion theory and the experiential nature of media richness perceptions. Academy of Management Journal, 42(2), 153-170.

Chaisatien, P. \& Akahori, K. (2007). An Application on 3G Mobile Phone and Two Dimension Barcode in Classroom Communication Support System. In C. Montgomerie \& J. Seale (Eds.), Proceedings of EdMedia: World Conference on Educational Media and Technology 2007 (pp. 3320-3329). Association for the Advancement of Computing in Education (AACE).

Clark, R. C., \& Mayer, R. E. (2016). E-learning and the Science of Instruction: Proven Guidelines for Consumers and Designers of Multimedia Learning. John Wiley \& Sons.

Creswell, J. W. (2004). Educational Research: Planning, Conducting, and Evaluating Quantitative and Qualitative Research. Pearson.

Daft, R. \& Lengel, R. (1984). Information richness: A new approach to managerial behavior and organization design. B. M. Staw \& L. L. Cummings (Ed.), Research in Organizational Behavior, 6, 191- 233. Greenwich, CT: JAI Press.

Daft, R. L. \& Lengel, R.H. (1986). Organizational information requirements, media richness and structural design. Management Science, 32(5), 554-571.

Daft, R., Lengel, R. \& Trevino, L. (1987). Message equivocality, media selection, and manager performance: Implications for information systems. MIS Quarterly, 17, 355-366.

Davis, F. D. (1985). A technology acceptance model for empirically testing new end-user information systems: Theory and results (Doctoral dissertation, Massachusetts Institute of Technology).

Durak, G., Ozkeskin, E., \& Ataizi, M. (2016). QR codes in education and communication. Turkish Online Journal of Distance Education-TOJDE, 17(2), 42-58.

Erdoğdu, E. (2016). Açık ve uzaktan öğrenme kapsamında etkileşimli ekitaplar: etkileşim, teknoloji, üretim boyutu ve örnekleri. AUAd, 2(3),88-114.

George, D., \& Mallery, M. (2010). SPSS for Windows Step by Step: A Simple Guide and Reference, 17.0 update (10a ed.). Boston: Pearson.

Goyal, S., Yadav, S., \& Mathuria, M. (2016, September). Exploring concept of QR code and its benefits in digital education system. In Advances in Computing, Communications and Informatics (ICACCI), 2016 International Conference on (pp. 1141-1147). IEEE. 
Hwang, G. J., Wu, C. H., Tseng, J. C. R., \& Huang, I. (2011). Development of a ubiquitous learning platform based on a real-time help-seeking mechanism. British Journal of Educational Technology, 42(6), 9921002.

Karadeniz, A. (2011). Multimedya destekli web tabanlı çalışma kitabının hazırlanması ve etkinliğinin araştırılması. Yüksek lisans tezi. Dokuz Eylül Üniversitesi, Eğitim Bilimleri Enstitüsü, İzmir.

Kato, H., Tan, K. T., \& Chai, D. (2010). Barcodes for mobile devices. Cambridge University Press.

Kouninef, B., Merad, G., \& Djelti, M. (2015, October). The use of QR codes and mobile technology in the blended learning approach. In e-Learning (econf), 2015 Fifth International Conference on (pp. 135-143). IEEE.

Lai, H. C., Chang, C. Y., Wen-Shiane, L., Fan, Y. L., \& Wu, Y. T. (2013). The implementation of mobile learning in outdoor education: application of QR codes. British Journal of Educational Technology, 44(2), 57-E62.

Law, C. \& So, S. (2010). QR codes in education. Journal of Educational Technology Development and Exchange, 3(1), 85-100.

Lee, J. K., Lee, I. S., \& Kwon, Y. J. (2011). Scan \& learn! Use of quick response codes \& smartphones in a biology field study. The american biology Teacher, 73(8), 485-492.

Lezhebokov, A. A., Kravchenko, Y. A., \& Bova, V. V. (2014, October). Support system for QR-code-based educational processes. In Application of Information and Communication Technologies (AICT), 2014 IEEE 8th International Conference on (pp. 1-4). IEEE.

Liu, T. Y., Tan, T. H., \& Chu, Y. L. (2010). QR code and augmented reality-supported mobile English learning system. In Mobile Multimedia Processing (pp. 37-52). Springer Berlin Heidelberg.

Liu, T., Tan, T., \& Chu, Y. (2007). 2D Barcode and Augmented Reality Supported English Learning System. Proceeding of the 6th IEEE/ACIS International Conference on Computer and Information Science (pp 5-10). IEEE Computer Society

Looi, C.K., Wong, L.H., So, H.J., Seow, P., Toh, Y., Chen, W., Zhang, B., Norris, C. and Soloway, E (2009). Anatomy of a mobilized lesson: Learning my way. Computers E Education, 53(4), 1120-1132.

Mayer, R. E., \& Moreno, R. (2003). Nine ways to reduce cognitive load in multimedia learning. Educational Psychologist, 38(1), 43-52.

McCabe, M., \& Tedesco, S. (2012). Using QR codes and mobile devices to foster an inclusive learning environment for mathematics education. International Journal of Technology and Inclusive Education (IJTIE), 1(1).

Ozcelik, E., \& Acarturk, C. (2011). Reducing the spatial distance between printed and nline information sources by means of mobile technology enhances learning: Using 2D barcodes. Computers $\mathcal{E}$ Education, 57(3), 2077-2085.

Pérez-Sanagustín, M., Parra, D., Verdugo, R., García-Galleguillos, G., \& Nussbaum, M. (2016). Using QR codes to increase user engagement in museum-like spaces. Computers in Human Behavior, 60, 73-85.

Rikala, J. (2014). Evaluating QR code case studies using a mobile learning framework. International Association for Development of the Information Society.

Rogers, E. M. (2010). Diffusion of Innovations. Simon and Schuster.

Suh, K. S. (1999). Impact of communication medium on task performance and satisfaction: An examination of media-richness theory. Information E Management, 35(5), 295-312.

Trifonova, A. (2003). Mobile learning: review of the literature. Technical Report DIT-03-009, Informatica eTelecomunicazioni, University of Trento. http://eprints.biblio.unitn.it/archive/00000359/01/009.pdf

Winter, M. (2011). Scan Me-Everybody's Guide to the Magical World of Qr Codes. Westsong Publishing.

Yfantis, V., Kalagiakos, P., Kouloumperi, C., \& Karampelas, P. (2012, July). Quick response codes in elearning. In Education and e-Learning Innovations (ICEELI), 2012 International Conference on (pp. 1-5). IEEE. 
Youan, X., Chao, Y., \& Chunling, L. (2011, April). A new method of QR code accumulation encoding in mobile education. In Consumer Electronics, Communications and Networks (CECNet), 2011 International Conference on (pp. 42-45). IEEE. 